\title{
Téoros
}

Revue de recherche en tourisme

\section{L'hôtellerie au Québec de 1989 à 2003}

Un bilan très mitigé

\section{Jean Stafford}

Volume 23, numéro 3, automne 2004

Regards sur l'hôtellerie : un secteur en mutation

URI : https://id.erudit.org/iderudit/1071228ar

DOI : https://doi.org/10.7202/1071228ar

Aller au sommaire du numéro

Éditeur(s)

Université du Québec à Montréal

ISSN

0712-8657 (imprimé)

1923-2705 (numérique)

Découvrir la revue

Citer cet article

Stafford, J. (2004). L’hôtellerie au Québec de 1989 à 2003 : un bilan très mitigé.

Téoros, 23(3), 22-23. https://doi.org/10.7202/1071228ar d'utilisation que vous pouvez consulter en ligne.

https://apropos.erudit.org/fr/usagers/politique-dutilisation/ 


\section{L'hôtellerie au Québec de 1989 à 2003

\author{
Un bilan très mitigé
}

\section{Jean Stafford}

L'hôtellerie est au tourisme ce que la route est aux voitures : nécessaire, mais insuffisante. L'hôtellerie est un substrat du tourisme, mais le tourisme peut exister sans le secteur hôtelier. Ce mode particulier d'hébergement est un élément important de l'offre touristique. Son état de santé et son évolution vont contribuer à freiner ou à accélérer le développement touristique, de là l'importance d'étudier les performances de ce secteur.

\section{L'étude du passé}

La situation du parc hôtelier au Québec, perçue dans son ensemble, varie très peu dans le temps. Ainsi, des années 1989 à 2003, la croissance (le taux d'accroissement annuel moyen) a été de $1,08 \%$ pour les chambres disponibles et de $1,28 \%$ pour les chambres occupées. Il est possible de décortiquer cette évolution en observant des blocs de cinq années (voir tableau 1).

TABLEAU 1: Les taux d'accroissement annuel moyen* des chambres disponibles, des chambres occupées ef des taux d'occupation au Québec, par blocs de cinq années, de 1989 à 2003 (en pourcentage)

\begin{tabular}{|c|c|c|c|}
\hline \multirow{2}{*}{ Période } & \multicolumn{2}{|c|}{ Chambres } & $\begin{array}{c}\text { Taux } \\
\text { d'occupation } \\
\end{array}$ \\
Disponibles & Occupées & \\
\hline $1989-1993$ & 1,04 & $-1,66$ & $-2,72$ \\
\hline $1994-1998$ & 0,42 & 2,45 & 2,02 \\
\hline $1999-2003$ & 1,93 & 1,68 & $-0,24$ \\
\hline $1989-2003$ & 1,08 & 1,28 & 0,19 \\
\hline
\end{tabular}

* Il s'agit d'une moyenne géométrique. Source: Nos calculs, à partir des données de Tourisme Québec.
L'étude de l'évolution du parc hôtelier par blocs de cinq années montre une très faible croissance des chambres disponibles; cette croissance reste positive, mais on peut remarquer un creux dans la période 1994-1998 (le taux d'accroissement est alors de 0,42\%). Les chambres occupées connaissent une baisse dans la période 1989-1993 (-1,66\%); il y a ensuite une progression positive de $2,45 \%$ par année durant la période 1994-1998. La période la plus récente (1999-2003) montre une croissance moins soutenue, soit $1,28 \%$ par année.

Les taux d'occupation, qui peuvent être considérés comme des indicateurs de performance du parc hôtelier, indiquent une baisse annuelle de $-2,72 \%$ durant la période 1989-1993. On assiste ensuite à une croissance positive durant la période 1994-1998 (2,02\%) et le dernier bloc de cinq années (1999-2003) montre une baisse annuelle très faible de $-0,24 \%$ par année. Dans l'ensemble des quinze dernières années (1989-2003), la croissance des taux d'occupation a été presque nulle, avec $0,19 \%$ par année. On peut donc constater que la performance globale du secteur hôtelier n'est pas très reluisante.

\section{Les mouvements cycliques}

Dans l'ensemble, le parc hôtelier québécois est peu influencé par les mouvements cycliques ; l'écart type de ces mouvements est de $3,28 \%$ dans le cas des chambres disponibles et de 3,19\% dans celui des chambres occupées. L'évolution cyclique du parc hôtelier est résumée au tableau 2. On constate qu'il y a un cycle négatif en 1993, commun aux chambres disponibles et aux chambres occupées, et deux cycles positifs pour les années 1990 et 1995. Par ailleurs, en 1988-1989 et de 1998 à 2003, les chambres occupées connaissent un cycle positif alors que les
TABLEAU 2: L'évolution cyclique du parc hôtelier au Québec ; les cycles positits ef négatifis* des chambres disponibles ef des chambres occupées

\begin{tabular}{|c|c|c|c|}
\hline & \multicolumn{2}{|c|}{ Chambres disponibles } \\
\hline & & - & + \\
\hline \multirow{2}{*}{$\begin{array}{l}\text { Chambres } \\
\text { occupées }\end{array}$} & + & $\begin{array}{c}1988-1989 \\
1998 \text { à } 2003\end{array}$ & 1990 et 1995 \\
\hline & - & 1993 & $\begin{array}{c}1991-1992 \\
1994 \\
1996-1997\end{array}$ \\
\hline
\end{tabular}

* Le signe + indique un cycle positif (supérieur à l'indice 100) et le signe - un cycle négatif (inférieur à l'indice 100).

Source: Nos calculs, à partir des données de Tourisme Québec.

chambres disponibles montrent un cycle négatif. La situation est inversée en 1991-1992, en 1994 et en 1996-1997 où les chambres disponibles ont des cycles positifs et les chambres occupées des cycles négatifs. Les mouvements cycliques sont peu importants pour la compréhension de l'évolution du parc hôtelier du Québec ; ils ne gênent en rien la formulation des prévisions.

\section{Le futur proche}

En tenant compte de la situation des quinze dernières années, on peut affirmer que le parc hôtelier québécois aura une croissance très faible dans le futur proche. De 2004 à 2006, le taux d'accroissement annuel moyen des chambres disponibles sera de $0,91 \%$ et celui des chambres occupées de $1,01 \%$; pour la même période ; le taux d'occupation, quant à lui, oscillera de $52,2 \%$ à $52,7 \%$ (voir les principaux résultats prévisionnels au tableau 3 ). 


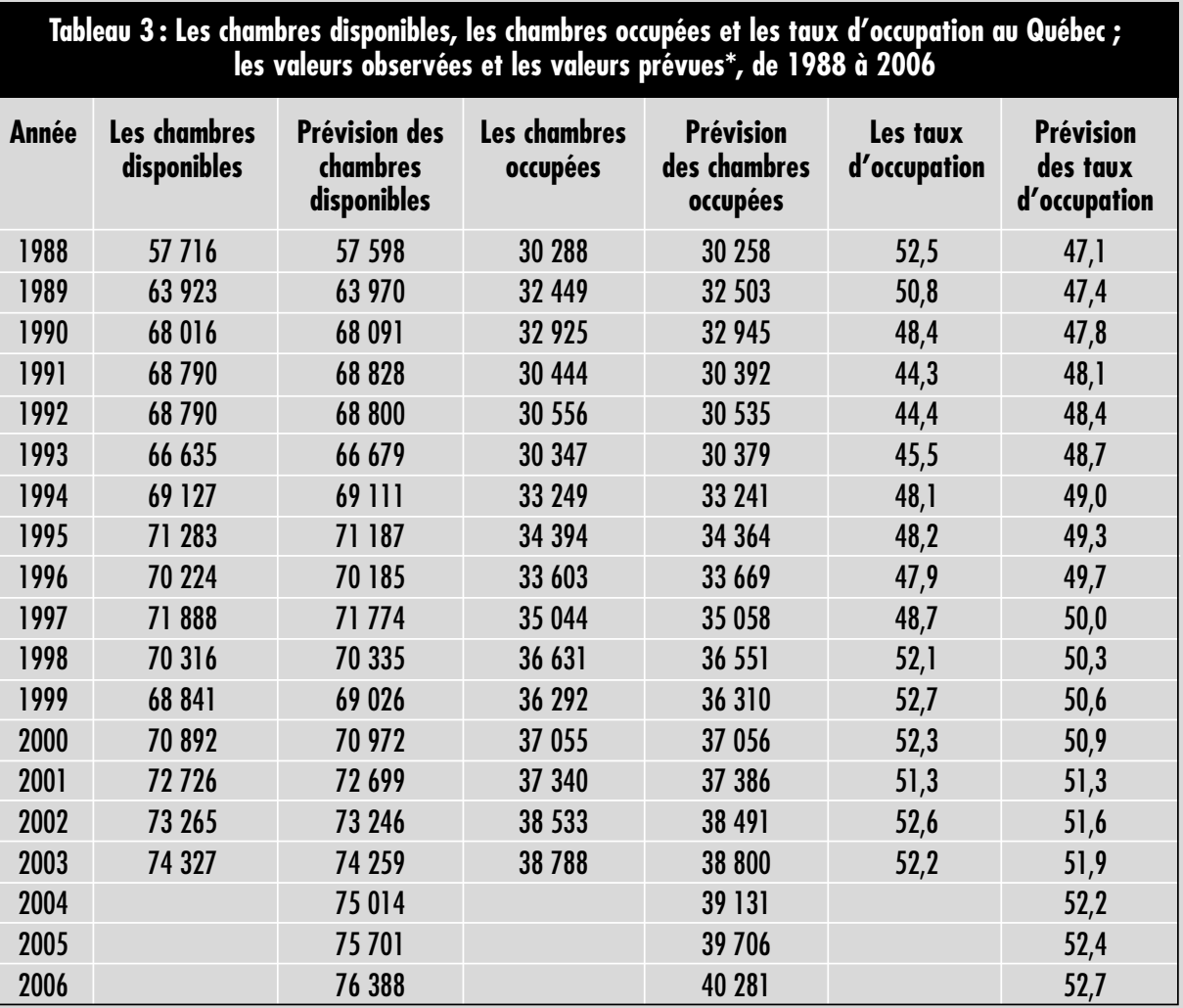

Le parc hôtelier du Québec bouge peu et lentement; il n'est pas complètement inerte, mais un peu amorphe. Le seul aspect positif est que les prévisions quantitatives, calculées à partir de cette situation, sont faciles et sans surprise.

L'hôtellerie n'est pas un pur reflet du tourisme, mais demeure un pilier nécessaire à son développement; la stagnation de ce secteur n'est pas de bon augure pour l'avenir du tourisme au Québec.

Jean Stafford est économiste et professeur au Département d'études urbaines et touristiques de l'Université du Québec à Montréal.

* Les valeurs prévues pour les chambres disponibles et les chambres occupées sont obtenues par une tendance linéaire couplée à un cycle conjoncturel.

Source: Nos calculs, à partir des données de Tourisme Québec.

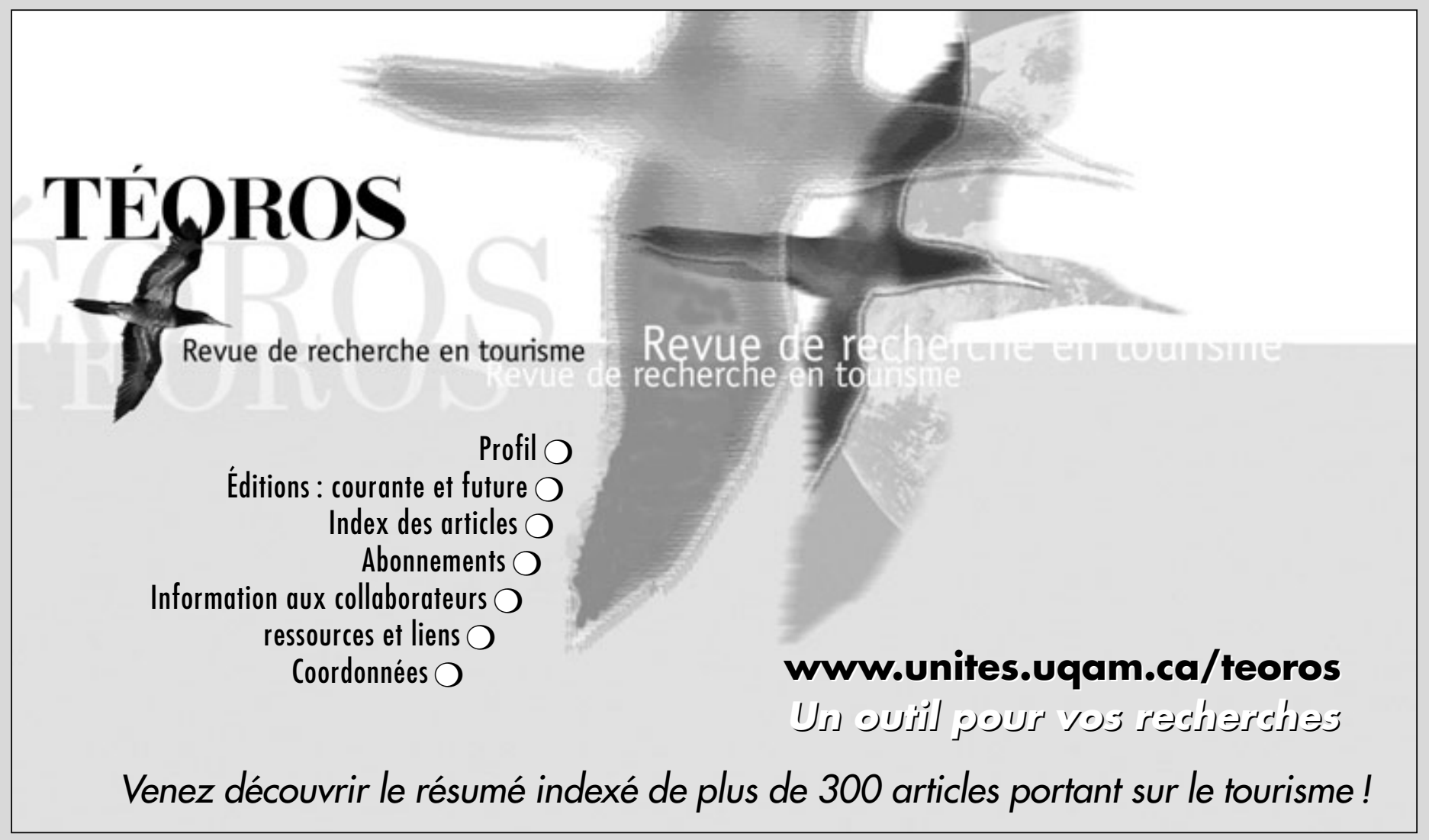

